\title{
Design and Analysis for Loss Reduction of High-Speed Permanent Magnet Motor using a Soft Magnetic Composite
}

\author{
Sung-Ho Lee ${ }^{1}$, Yong-Jae Kim ${ }^{2}$, Kyu-Seok Lee ${ }^{1}$, and Sung-Jin Kim ${ }^{1,2 *}$ \\ ${ }^{1}$ Seonam Regional Division, Korea Institute of Industrial Technology, Gwangju 61012, Korea \\ ${ }^{2}$ Department of Electrical Engineering, Chosun University, Gwangiu 61452, Korea
}

(Received 1 October 2015, Received in final form 6 November 2015, Accepted 9 November 2015)

\begin{abstract}
Soft magnetic composites (SMCs) are especially suitable for the construction of low-cost, high-performance motors with 3-D magnetic fields. The main advantages of SMCs is that the iron particles are insulated by the surface coating and adhesive used for composite bonding, the eddy-current loss is much lower than that in laminated steels, especially at higher frequencies, and the hysteresis loss becomes the dominant component of core losses. These properties enable machines to operate at higher frequencies, resulting in reduced machine size and weight. In this paper, 3-D topologies are proposed that enable the application of SMCs to effectively reduce losses in high-speed permanent magnet (PM) motors. In addition, the electromagnetic field characteristics of the motor topologies are evaluated and compared using a non-linear finite element method (FEM) based on 3-D numerical analysis, and the feasibility of the motor designs is validated.
\end{abstract}

Keywords : soft magnetic composite (SMC), high-speed permanent magnet (PM) motor, finite element method (FEM), core loss, 3-D numerical analysis

\section{Introduction}

Soft magnetic composites (SMCs) produced by powder metallurgy techniques possess a number of advantages over the conventional laminated steels commonly used in electrical machines, and have undergone significant recent developments [1]. Compared with traditional silicon steel sheets, SMCs have the following advantages. First, SMCs are in general, magnetically isotropic because of their powdered nature, and, are therefore suitable for the construction of electrical machines that are subjected to 3D magnetic fluxes and have complex structures $[2,3]$. This isotropic magnetic property opens up crucial design benefits, and allows magnetic circuits to be designed with 3-D flux paths. Second, SMCs are manufactured for the core of the motor as modules, so they are suitable for motors with complex structures. In addition, the core can be made by a press-molding process, which makes mass production easy [3, 4]. Third, the iron particles are insulated by the surface coating and adhesive used for

\footnotetext{
(C)The Korean Magnetics Society. All rights reserved.

*Corresponding author: Tel: +82-62-230-7034

Fax: +82-62-230-7026, e-mail: kimsj641@chosun.kr

'S. H Lee and Y. J Kim contributed equally to this work.
}

composite bonding, the eddy-current loss is much lower than that in laminated steels, especially at higher frequencies, and the hysteresis loss becomes the dominant component of core losses. These properties may allow machines to operate at higher frequencies, resulting in reduced machine size and weight. Fourth, SMCs are cheap, so their use can significantly reduce material costs [5-7]. Fifth, SMCs are easy to recycle, and finally, alloy powders such as $\mathrm{Fe}-\mathrm{Ni}, \mathrm{Fe}-\mathrm{Si}, \mathrm{Fe}-\mathrm{P}$, and $\mathrm{Fe}-\mathrm{Si}-\mathrm{Al}$, which are important as admixtures or for the special application of these composites, can sometimes be used [8-13]. Therefore, in this paper, 3-D topologies are proposed that use SMCs to effectively reduce losses in high-speed PM motor. The electromagnetic field characteristics of the motor topologies are evaluated and quantitatively compared using a non-linear finite element method (FEM) based on 3-D numerical analysis, and the feasibility of the motor designs is validated.

\section{Design Specifications of High-speed Permanent Magnet Motor}

\subsection{Magnetic properties of material}

Fig. 1 shows the real magnetization properties of the silicon steel and SMC used in a high-speed PM motor. 


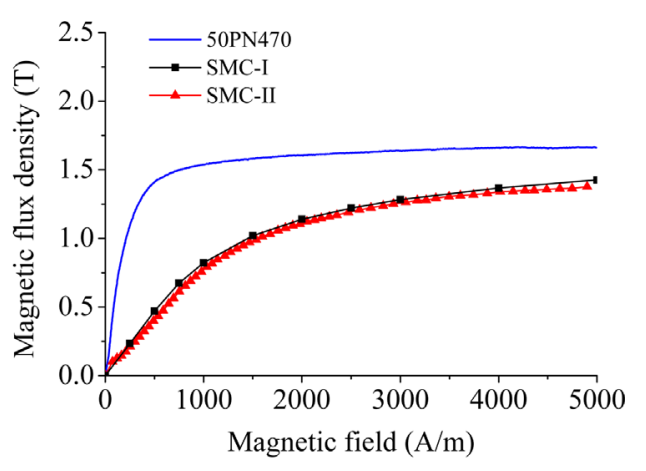

(a)

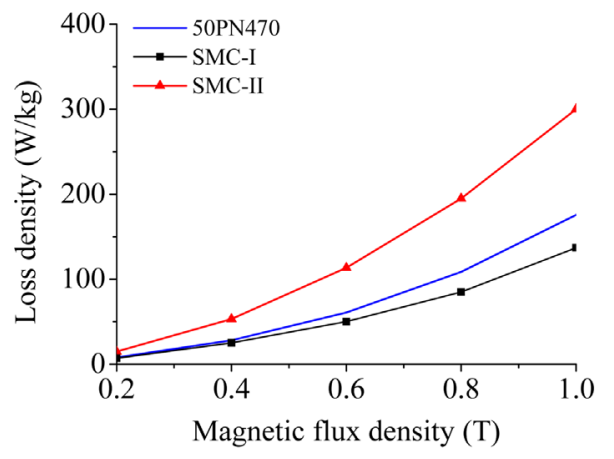

(b)

Fig. 1. (Color online) Magnetization properties of core material: (a) magnetic flux density, (b) core loss property at $1 \mathrm{kHz}$.

The magnetic flux density and core loss were measured using the sample sheet and test ring core provided by the manufacturer, and the measured magnetization properties were applied in the FEM analysis and design. Silicon steel of type 50PN470 was used. This is produced by POSCO, and has a maximum magnetic flux density of 1.7 $\mathrm{T}$ at $5000 \mathrm{~A} / \mathrm{m}$. The thickness of one steel sheet is 0.5 $\mathrm{mm}$, and its density is $7700 \mathrm{~kg} / \mathrm{m}^{3}$. SMC-I and SMC-II are commercial powders. These have a maximum magnetic flux density of $1.42 \mathrm{~T}$ and $1.39 \mathrm{~T}$ at $5000 \mathrm{~A} / \mathrm{m}$, respectively. Their density is $7570 \mathrm{~kg} / \mathrm{m}^{3}$ and $7340 \mathrm{~kg} / \mathrm{m}^{3}$,

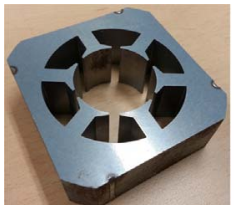

(a)

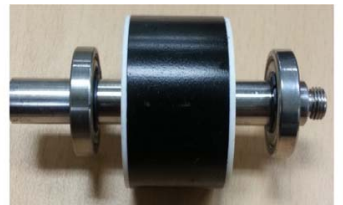

(b)

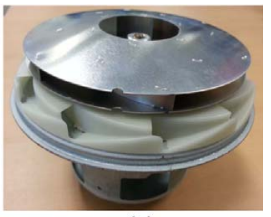

(c)
Fig. 2. (Color online) Prototype of the high-speed permanent magnet motor with laminated silicon steel 50PN470: (a) laminated stator without winding, (b) laminated rotor, (c) stator, rotor, and impeller assembly.

Table 1. Specifications of high-speed motor with laminated silicon steel.

\begin{tabular}{cc}
\hline \hline Parameter & Value $($ Unit $)$ \\
\hline Poles/Phases/Slots & $4 / 3 / 6$ \\
Rated output power & $0.85(\mathrm{~kW})$ \\
Rated speed & $25000(\mathrm{rpm})$ \\
Rated current & $8.3\left(\mathrm{~A}_{\mathrm{pk}}\right)$ \\
DC Link voltage & $310\left(\mathrm{~V}_{\mathrm{dc}}\right)$ \\
PM Property & Bonded NdFeB@0.7 $(\mathrm{T})$ \\
Number of nodes & 13,455 \\
Number of elements & 41,229 \\
\hline
\end{tabular}

respectively.

\subsection{Motor specifications}

Fig. 2 shows the prototype of the high-speed motor with laminated silicon steel 50PN470. Fig. 2(a) shows the laminated stator without winding, Fig. 2(b) shows the laminated rotor, and Fig. 2(c) shows the stator, rotor, and impeller assembly. The high-speed PM motor has 4 poles and 6 slots, surface mounted type with a rated speed of $25,000 \mathrm{rpm}$ and rated power of $0.85 \mathrm{~kW}$. Its DC link voltage is $310 \mathrm{~V}_{\mathrm{dc}}$ and rated current is $8.3 \mathrm{~A}_{\mathrm{pk}}$. Fig. 3 shows the 3-D shape of the high-speed PM motor, with Fig. 3(a) shows 3-D geometry model, Fig. 3(b) shows 3D FE model, and Fig. 3(c) shows the cross sectional view.

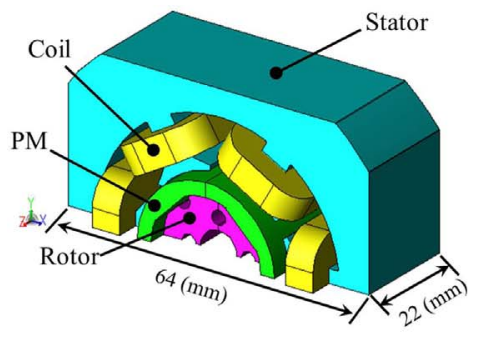

(a)

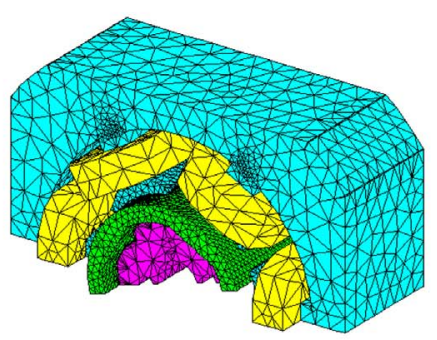

(b)

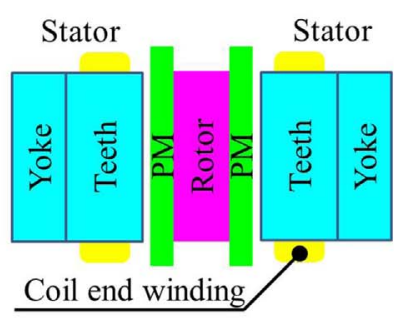

(c)

Fig. 3. (Color online) 3-D shape of the high-speed permanent magnet motor: (a) 3-D geometry model, (b) 3-D FE model (c) crosssectional view. 
Table 1 shows the specifications of the high speed motor with laminated silicon steel.

\section{Proposed 3-D Shape of High-speed Per- manent Magnet Motor for Loss Reduction}

\subsection{Loss reduction design}

Fig. 4 shows the 3-D topology of the designed models (without winding) using SMCs. Table 2 shows the stator concept of each model. For a fair comparison, each model shares the following design criteria:

- Same external dimension of the motor;

- Same rated speed and output power;

- Same PM, rotor material;

An SMC was applied to only the stator of the motor. The rotor used conventional laminated silicon steel, which has a higher density than the SMC. This ensures structural stability, because it is rotating at high speed, meaning the core loss in the rotor is lower than the total core loss. As shown in Fig. 4 and Table 2, the teeth and

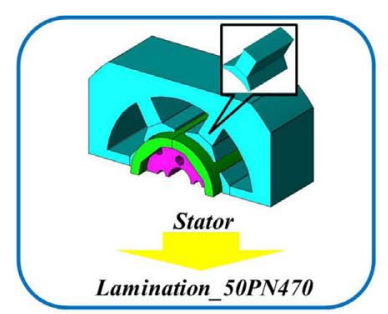

(a)

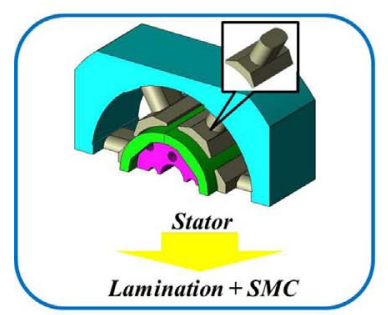

(c)

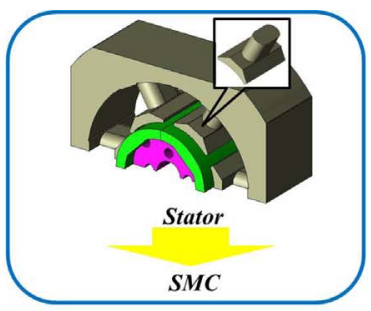

(b)

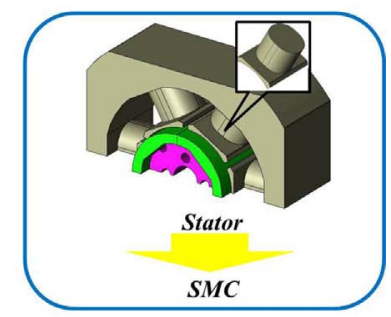

(d)

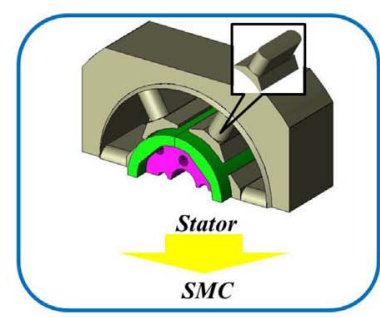

(e)

Fig. 4. (Color online) 3-D topology of the designed models (without winding) using SMC: (a) laminated model, (b) proposed model I, (c) proposed model II, (d) proposed model III, (e) proposed model IV.
Table 2. (Color online) Stator concept of each model.

\begin{tabular}{|c|c|c|c|c|c|}
\hline & $\begin{array}{l}\text { Laminated } \\
\text { model }\end{array}$ & $\begin{array}{c}\text { Proposed } \\
\text { model I }\end{array}$ & $\begin{array}{c}\text { Proposed } \\
\text { model II }\end{array}$ & $\begin{array}{l}\text { Proposed } \\
\text { model III }\end{array}$ & $\begin{array}{l}\text { Proposed } \\
\text { model IV }\end{array}$ \\
\hline $\begin{array}{c}\text { Yoke } \\
\text { material }\end{array}$ & $\begin{array}{l}\text { Silicon } \\
\text { steel }\end{array}$ & SMC & $\begin{array}{c}\text { Silicon } \\
\text { steel }\end{array}$ & SMC & SMC \\
\hline $\begin{array}{c}\text { Teeth } \\
\text { material }\end{array}$ & Silicon steel & SMC & SMC & SMC & SMC \\
\hline $\begin{array}{c}\text { Teeth } \\
\text { shape } \\
\text { (z-axis) }\end{array}$ & 22 & $12 \underset{6}{6}$ & 6 & 13 & \\
\hline Teeth area & 132 & 64.2 & 64.2 & 130 & 124.2 \\
\hline $\begin{array}{c}\text { Yoke length } \\
\text { (z-axis) }\end{array}$ & 22 & 22 & 22 & 22 & 20 \\
\hline
\end{tabular}

yoke of the stator were designed using the advantages of SMCs, allowing the magnetic circuits to be freely designed with 3-D flux paths. SMCs were used for the teeth and the yoke of the proposed model I, and the shape of the teeth was designed to reduce loss and to be compact in terms of coil end winding. The coil end winding had a length of $5 \mathrm{~mm}$ in the prototype laminated model and the length of the teeth was determined to be $12 \mathrm{~mm}$. Compared to the laminated model, the weight of the coil could be reduced by $50 \%$. In addition, the area of the teeth was reduced by $50 \%$ compared with the laminated model because of the saturation of the magnetic flux density. The shape of the proposed model II is the same as that of the proposed model I, but the material of each yoke is different. The yoke of the proposed model II used the silicon steel. SMCs were used in both the teeth and the yoke of the proposed model III, as in the proposed model I. The design of the proposed model III also considered the slot fill factor for loss reduction, and improved the saturation of magnetic flux density generated in the proposed models I and II. As a result, the teeth area of the proposed model III was approximately equal to that of the laminated model. Finally, in the proposed model IV, chamfering was conducted using the teeth of the laminated model. Moreover, the length of the yoke (z-axis) was designed to be $20 \mathrm{~mm}$, an attempt to reduce core loss by reducing the weight of the yoke.

\subsection{3-D Numerical analysis results and performance comparison}

To accurately analyze the five high-speed motor models with different stators, the electromagnetic field must be calculated for the five-stator topologies. Thus, after the motor has been properly modeled, the electromagnetic 


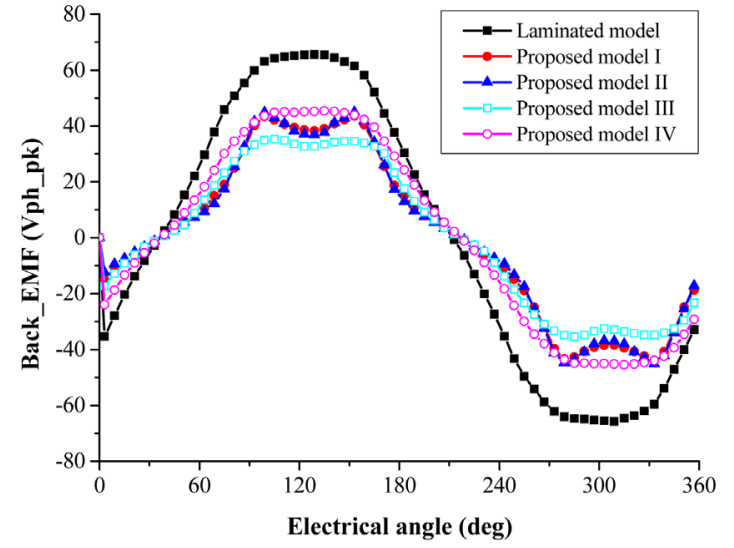

(a)

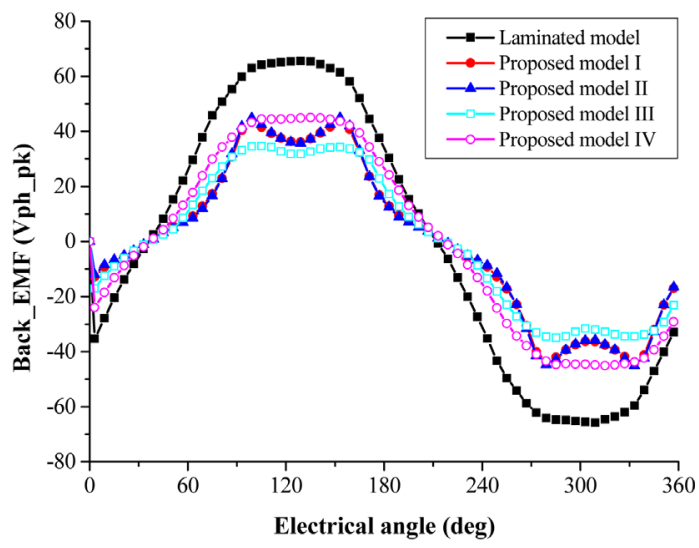

(b)

Fig. 5. (Color online) Back_EMF waveforms (U-phase): (a) Proposed model with SMC-I, (b) Proposed model with SMC-II.

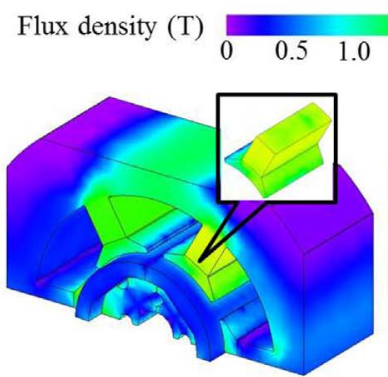

(a)

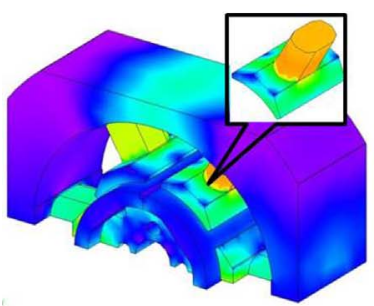

(c)

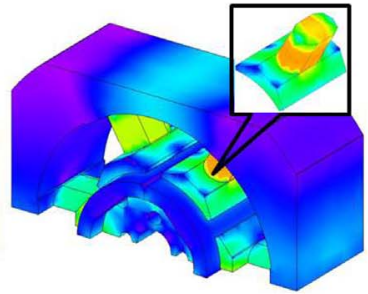

(b)

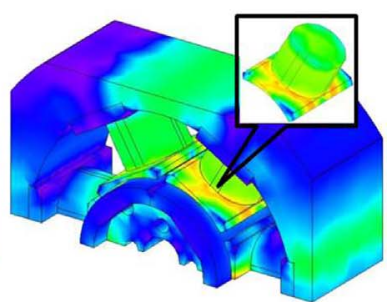

(d)

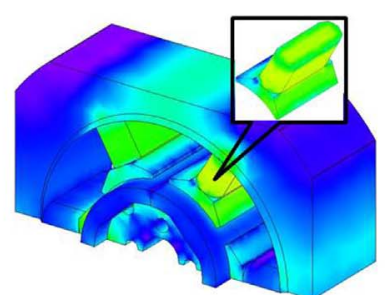

(e)
Fig. 6. (Color online) Magnetic flux distribution of each model using SMC-I: (a) laminated model, (b) proposed model I, (c) proposed model II, (d) proposed model III, (e) proposed model IV.

field of the five motor models was calculated at the rated output power $($ Pout $=0.85 \mathrm{~kW}$ ). At the same output power, the coil diameter and number of turns was designed to improve current density of the laminated model. As a

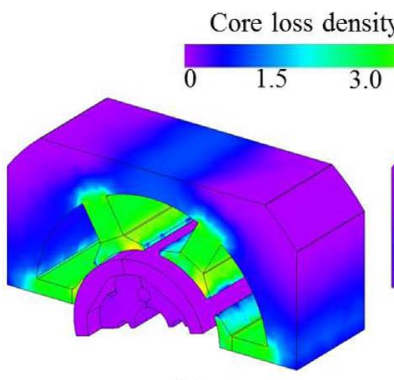

(a)

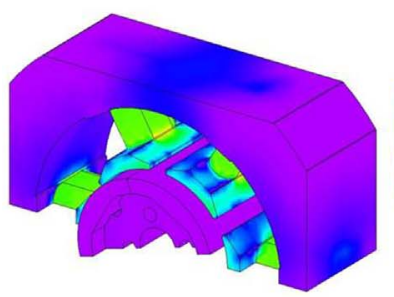

(c)

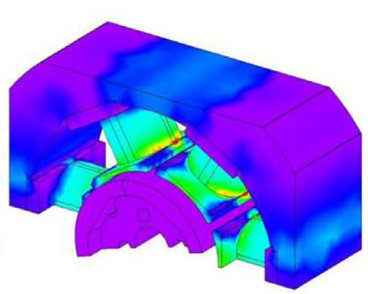

(d)

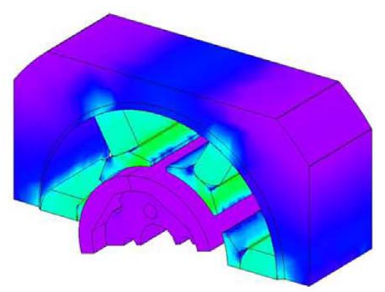

(e)

Fig. 7. (Color online) The core loss distribution of each model using SMC-I: (a) laminated model, (b) proposed model I, (c) proposed model II, (d) proposed model III, (e) proposed model IV.

result, the proposed model I gave the biggest reduction of the design models using SMC-I. This is a reduction of $17 \%$ compared with the laminated model. Fig. 5 shows the Back_EMF waveforms (U-phase) of each model. Fig. 
Table 3. Design results of each model using SMC-I.

\begin{tabular}{cccccc}
\hline \hline & Laminated model & Proposed model I & Proposed model II & Proposed model III & Proposed model IV \\
\hline Input Current (A) & 8.4 & 15.3 & 15.5 & 16.5 & 11.6 \\
Number of turns & 36 & 30 & 30 & 22 & 27 \\
Coil diameter (mm) & 0.8 & 1.2 & 1.2 & 1.2 & 1.2 \\
Slot area (mm ${ }^{2}$ ) & 151.5 & 169.2 & 169.2 & 121.1 & 151.5 \\
Current density (A/mm ${ }^{2}$ ) & 11.6 & 9.6 & 9.7 & 10.3 & 7.2 \\
Torque (Nm) & 0.32 & 0.32 & 0.32 & 0.32 & 0.32 \\
Torque ripple (\%) & 17.09 & 8.13 & 29.23 & 19.58 & 15.85 \\
Core loss (W) & 39.0 & 27.9 & 14.4 & 32.8 & 33.0 \\
Copper loss (W) & 26.4 & 14.1 & 95.0 & 94.3 & 12.1 \\
Efficiency (\%) & 92.9 & 95.3 & & 94.5 & 94.9 \\
\hline
\end{tabular}

Table 4. Design results of each model using SMC-II.

\begin{tabular}{|c|c|c|c|c|c|}
\hline & Laminated model & Proposed model I & Proposed model II & Proposed model III & Proposed model IV \\
\hline Input Current (A) & 8.4 & 16.0 & 16.0 & 16.7 & 11.7 \\
\hline Number of turns & 36 & 30 & 30 & 22 & 27 \\
\hline Coil diameter (mm) & 0.8 & 1.2 & 1.2 & 1.2 & 1.2 \\
\hline Slot area $\left(\mathrm{mm}^{2}\right)$ & 151.5 & 169.2 & 169.2 & 121.1 & 151.5 \\
\hline Current density $\left(\mathrm{A} / \mathrm{mm}^{2}\right)$ & 11.6 & 10.0 & 10.0 & 10.4 & 7.3 \\
\hline Torque $(\mathrm{Nm})$ & 0.32 & 0.32 & 0.32 & 0.32 & 0.32 \\
\hline Torque ripple (\%) & 17.09 & 8.44 & 10.41 & 19.79 & 15.79 \\
\hline Core loss $(\mathrm{W})$ & 39.0 & 55.8 & 48.6 & 64.0 & 64.5 \\
\hline Copper loss (W) & 26.4 & 15.4 & 15.4 & 16.8 & 12.3 \\
\hline Efficiency (\%) & 92.9 & 92.3 & 93.0 & 91.3 & 91.7 \\
\hline
\end{tabular}

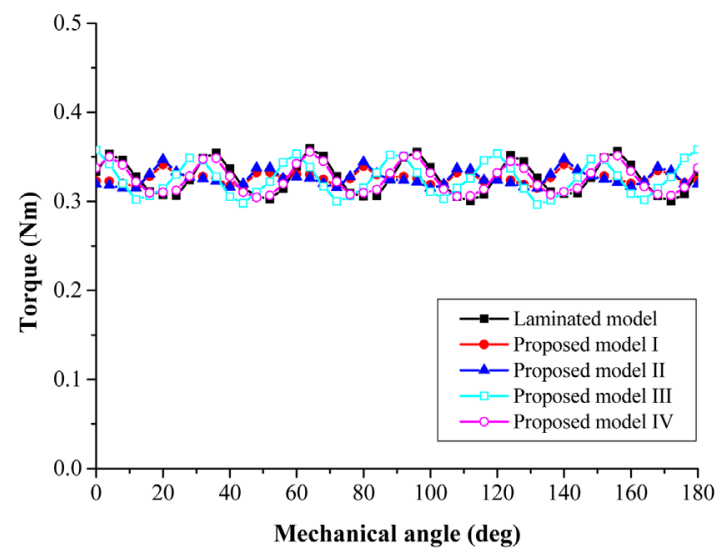

(a)

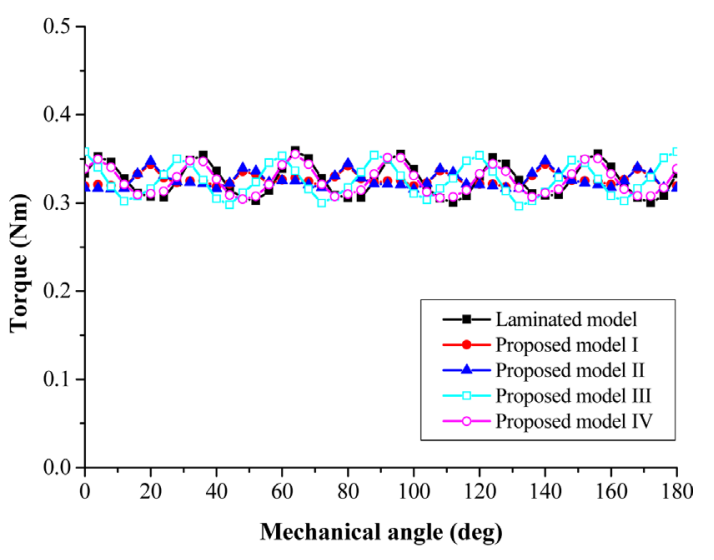

(b)

Fig. 8. (Color online) Torque waveforms: (a) Proposed model with SMC-I, (b) Proposed model with SMC-II.

6 shows the magnetic flux distribution of each model using SMC-I, as obtained by the nonlinear FEM based on 3-D numerical analysis. As shown in Fig. 6, it was confirmed that magnetic flux was saturated in the teeth of the proposed models I, and II. Fig. 7 shows the core loss distribution of each model using SMC-I. The quantitative performance of the motors using each SMC is tabulated in Tables 3, and 4. Table 3 shows the design results of each model using SMC-I, and Table 4 shows those for the each model using SMC-II. From Tables 3, and 4, it can be seen that the input current needed for an output power of $850 \mathrm{~W}$, is higher than in the laminated model. As shown in Table 3, the proposed model I gave the biggest reduction in losses of the design models using SMC-I. This is a reduction of $35.3 \%$ compared with the laminated model. In the design models using SMC-II, proposed 
model II designed the best reduction in losses. However, as shown in Fig. 5(b), the magnetic flux density was saturated in the teeth of proposed model I. As shown in Fig. 5(d), (e), proposed models III and IV designed greater losses than proposed model I, but the saturation of magnetic flux density was improved. It was confirmed that the torque ripple is affecting the teeth shape. Fig. 8 shows the torque waveforms of each model.

\section{Conclusions}

In this paper, high-speed PM motor design using SMCs has been described. Various 3-D topologies were proposed to effectively reduce losses of in this motor by applying SMC materials. In addition, the electromagnetic field characteristics of the motor topologies were evaluated and quantitatively compared using a non-linear FEM based on 3-D numerical analysis, and the feasibility of the motor designs were validated. In future work, the results of this study will be verified by comparing them with those from a prototype motor.

\section{Acknowledgements}

This work was supported by the Global Excellent Technology Innovation of the Korea Institute of Energy Technology Evaluation and Planning (KETEP) granted financial resource from the Ministry of Trade, Industry \& Energy, Republic of Korea (No. 20135020900040).

\section{References}

[1] G. Cvetkovski, L. Petkovska, M. Cundev, and S. Gair, IEEE Trans. Magn. 38, 3165 (2002).

[2] G. Cvetkovski and L. Petkovska, IEEE Trans. Magn. 44, 3812 (2008).

[3] A. Reinap and M. Alakula, IEEE Trans. Magn. 48, 1613 (2012).

[4] Y. Shen, Z. Q. Zhu, J. T. Chen, R. P. Deodhar, and A. Pride, IEEE Trans. Magn. 49, 3830 (2013).

[5] F. Marignetti and V. D. Colli, IEEE Trans. Magn. 45, 2970 (2009).

[6] G. D. Donato, F. G. Capponi, and F. Caricchi, IEEE Trans. Ind. Electron. 60, 4831 (2013).

[7] T. Ishikawa, S. Sato, S. Takeguchi, and A. Matsuo, IEEE Trans. Magn. 48, 3132 (2012).

[8] Y. Huang, J. Zhu, and Y. Guo, IEEE Trans. Magn. 45, 4680 (2009).

[9] G. Lei, Y. G. Guo, J. G. Zhu, T. S. Wang, X. M. Chen, and K. R. Shao, IEEE Trans. Magn. 48, 923 (2012).

[10] Y. Guo, J. G. Zhu, and J. J. Zhong, IEEE Trans. Magn. 39, 3199 (2003).

[11] Y. Guo, J. G. Zhu, P. A. Watterson, and W. Wu, IEEE Trans. Ind. Appl. 39, 1696 (2003).

[12] S. Baserrah, K. Rixen, and B. Orlik, J. Magn. 17, 100 (2012).

[13] C. Goga, P. Lidija, C. Milan, and G. Sinclair, Int. J. Appl. Electromagn. Mecha. 13, 451 (2001). 